\title{
GRINGOS E PRECONCEITOS BRASILEIROS
}

\author{
Thaddeus Blanchette * \\ Ô gringo, não força. Deixa de ser imbecil. \\ Você que vem lá de fora quer entender do Brasil?
}

(175 Nada Especial, Gabriel o Pensador)

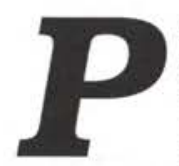

ara muitas pessoas, a única maneira sã e inteligente de falar em gringos $^{1}$ e preconceitos no Brasil é discursar sobre os preconceitos que estes têm em relação ao país. Isto porque o conceito de "preconceito" tem sido tão vinculado, na arena popular brasileira, à noção de racismo que falar daqueles que alguns brasileiros demonstram para com os estrangeiros - particularmente os oriundos do assim chamado primeiro mundo - parece bobagem. O Brasil, nessa acepção do mundo, é entendido como uma terra tolerante que acolhe qualquer estrangeiro, mas que tem uma queda particular pelos de pele branca, cidadãos da Europa Ocidental ou da América do Norte (acima do Rio Grande, é claro). A partir dessa perspectiva, a idéia de que um gringo possa eventualmente ser vítima de preconceitos por parte dos brasileiros é quase inconcebível e, quando alguém sugere esta possibilidade, na maioria dos casos é rapidamente corrigido pelos brasileiros que estão à sua volta. Como uma colega minha afirmou, pouco tempo depois da minha entrada no Museu Nacicnal como aluno: "Você não tem o direito de reclamar dos preconceitos, Tadeu. Afinal, esse país te concedeu a permissão de ficar por aqui, te concedeu uma vaga na universidade, te concedeu uma bolsa... Você tomou o lugar de um brasileiro legítimo em nosso sistema educacional e, se fosse minha a decisão, você não teria esse privilégio. Aliás, é bem possível que você só tenha conseguido uma vaga porque o Brasil tem preconceito do Brasil: estamos tão colonizados e falta tanto ao amor próprio que muita gente aqui pensa que qualquer gringo é melhor que qualquer brasileiro."

E aí está exemplificado o preconceito central que todo gringo residente no Brasil há de encontrar repetidamente durante a sua vida nesta terra: a afirmação de que ele não pode criticar nada do que é brasileiro, pois deve gratidão ao Brasil, país que tem demonstrado sua benevolência essencial por conceder a ele privilégios que são, de fato, estipulados como direitos pela Constituição. ${ }^{2}$ Para aumentar ainda mais a frustração do gringo, no momento em que é mandado calar a boca, seu interlocutor também o acusa de ter se beneficiado de preconceitos brasileiros que agem em seu favor preconceitos estes que resultam da lavagem cerebral colonialista de "outros brasileiros" (que quase nunca são especificados).

O preconceito é geralmente pensado no Brasil como atributo ou falha moral da personalidade individual. Observamos, porém, que ele também é alguma coisa possível de ser utilizada - existe como um fato social no sentido que lhe é dado por Durkheim (1978:88) - algo que é independente da vontade ou da psicologia de qualquer indivíduo. Além de uma ou outra pessoa ser preconceituosa, ela se utiliza dos preconceitos, principalmente para desqualificar outros em momentos de conflito, ou seja, alguém pode usar os preconceitos sem ser, dentro da definição popular da palavra, preconceituoso. Esta utilização encontra sua forma mais brasileira quando vemos a injunção da tolerância como justificativa para a exclusão e a desigualdade.
O Brasil, na acepção estereotipada e popular, é um país explorado pelos estrangeiros justamente por causa de sua tolerância. Vale a pena refletir, então, sobre o fato desta palavra ter um duplo sentido em português, sendo carregada de significados positivos e negativos. No sentido positivo, a "tolerância" significa a aceitação louvável das diferenças em costumes e hábitos manifestados entre os diversos ramos da família humana. Todavia, a "tolerância" também pode significar uma aceitação desmoralizante do caos social. Uma casa de tolerância, por exemplo, é um bordel, onde as normas sociais do sexo, reciprocidade e casamento são suspensas. No entendimento popular brasileiro, a "tolerância" é um conceito altamente associado ao poder e ao ritual hierarquizante de "você sabe com quem está falando?”, tão bem descrito por Roberto Da Matta (1979:139-193). No Brasil, falamos que uma pessoa "abusou da minha tolerância" quando ela insiste em questionar as hierarquias sociais que são apresentadas como naturais. Como Da Matta salienta, podemos falar em direitos e democracia no Brasil, mas os limites de tolerância são determinados pelo poder. Se alguém, numa posição inferior, insiste em ser tolerado, sua insistência é vista como uma intimidade inaceitável que merece o castigo (idem, 149-150).

Nesse sentido, as noções brasileiras de "tolerância" entram em conflito com os entendimentos modernos da sociologia e da psicologia acerca do preconceito, que é visto como um desajustamento que viola as normas sociologicamente estabelecidas do convívio e da justiça. (Allport, 1967; 
Adorno, 1950; Bauman, 1990). Tais "normas", porém, estão baseadas em noções iluministas de livre arbítrio, cidadania e governo que em nada são hegemonicamente estabelecidas no Brasil, como adverte Sérgio Buarque de Holanda (1973:9).

A primeira coisa que devemos entender, então, sobre os preconceitos contra os gringos no Brasil é que estão profundamente enraizados em uma visão natural e normalizante das hierarquias que compõem a sociedade brasileira, apesar desse sistema ser apresentado como igualitário pela lei-mór do país, a Constituição. A partir dessa visão, o lugar do estrangeiro é tido como naturalmente abaixo e atrás do filho nativo da terra, mas tal posicionamento é principalmente estipulado naqueles momentos em que um estrangeiro ou um grupo de estrangeiros desafia a ilusão da igualdade, entrando em conflito com brasileiros.

Vale a pena lembrar que também existem outros tipos de preconceito referentes aos gringos, por exemplo, um número pequeno mas expressivo de brasileiros que realmente sofrem de uma certa xenofobia, um desgosto exagerado em relação àquele que vem do exterior. Também há brasileiros que salientam preconceitos em favor dos gringos, dos quais falaremos mais adiante. Mas o preconceito mais encontrado pelo gringo em terras brasilis é o que costuma ser empregado por um brasileiro - não necessariamente preconceituoso - para desqualificar o estrangeiro $\mathrm{e}$ as suas opiniões em situações de enfrentamento.

Como sugere Bauman, o preconceito implica a manutenção de uma dupla moralidade, onde o comportamento que é considerado aceitável, em um caso, transforma-se em ultraje, em um outro, conforme as identidades sociais dos atores. Todavia, no Brasil, longe de gerar uma dupla moralidade, o preconceito muitas vezes a efetua. Quando Bauman fala que o preconceito permite a produção de atrocidades contra os forasteiros, ele sustenta suas palavras na noção de que, em uma determinada sociedade, existe um consenso objetivo e normativo sobre o que seja, de fato, uma atrocidade, e quem é um forasteiro. Este pode não ser o caso no
Brasil, onde o preconceito é utilizado para excluir aquelas pessoas que insistem em quebrar o consenso social e onde quem é rebaixado pelo preconceito em um dado momento pode ser tratado com uma pretensa igualdade em um outro - às vezes pela mesma pessoa! Assim, a característica utilizada para exclusão pela via do preconceito - seja de cor, gênero, orientação sexual, origem nacional e outros - é de importância secundária face do comportamento do ator a quem o adjetivo se aplica. Quando este mesmo ator quiser cobrar como direito o que a sociedade brasileira normaliza como privilégio, $\mathrm{e}$ quando essa cobrança entrar em conflito com os desejos de alguém que se considera superior em uma determinada escala social hierarquizada, o preconceito é ativado para mandar os macacos de volta aos seus devidos galhos. Nesses casos, as atrocidades formuladas para os que transgridem o consenso social não são entendidas como "injustiças" e sim como procedimentos normativos que devem ser aplicados àqueles que "abusam da nossa tolerância".

O preconceito no Brasil, então, manifesta-se em muitos momentos em função de uma lógica que é utilizada para excluir qualquer pessoa desagradável e, neste sentido, "gringo" é apenas um entre vários adjetivos que podem ser facilmente acoplados a estereótipos negativos, no mesmo plano de "gay", "negro", "mulher" etc. É importante reconhecer que, na sociedade brasileira, nenhuma dessas palavras necessariamente gera ou exprime o preconceito, mas todas elas podem ser facilmente utilizadas para efetivar a exclusão através de sua ligação a um arquivo de imagens preconcebidas. $\mathrm{O}$ preconceito pode ser utilizado, dessa forma, pelo indivíduo, sem ser incorporado como faceta duradoura de sua personalidade.

Seguem abaixo, então, alguns preconceitos comuns referentes aos gringos e deflagrados por brasileiros em momentos de conflito com estrangeiros, ilustrados por exemplos vindos da minha vida pessoal e de meu trabalho de campo entre gringos no Rio de Janeiro. Vale a pena avisar aqui que não quero afirmar que os gringos são um bando de pobres coitados que sofrem mais do que qualquer outro grupo social no Brasil, nem que as suas vidas nessas terras estejam predominantemente caracterizadas por uma luta ingrata e constante contra os preconceitos brasileiros. Ofereço esta lista unicamente como ilustração de como e quando um determinado tipo de preconceito é utilizado no Brasil na esperança de que isto possa servir como parte de um mapeamento dos preconceitos em geral.

\section{O gringo burro}

O estereótipo do "gringo burro" é talvez o mais utilizado por brasileiros em confrontos com gringos. Em termos de imagens visuais, esse gringo é tipicamente apresentado como corpulento e queimado pelo sol, vestido com uma camisa florida, meias pretas e sandálias ou tênis. Em termos sociais e políticos, o "gringo burro" é aquele que está completamente perdido e não tem a menor capacidade de desvendar realidades brasileiras sem que haja uma intercessão nativa. Atualmente, no Rio de Janeiro, o "gringo burro" é visto como estadunidense, mas ele tem sido identificado, em outros momentos e lugares no Brasil, como francês, inglês, alemão, ou até argentino.

Como indicam as palavras da canção do Gabriel o Pensador, citadas no início deste artigo, o "gringo burro" não entende nada do Brasil, portanto, sua opinião não vale coisa alguma quando ela se contrapõe a de um brasileiro "legítimo". Por isso, o estereótipo do "gringo burro" é geralmente empregado quando um brasileiro quer desqualificar o argumento de algum estrangeiro sem ter que discutir logicamente com ele.

Um exemplo recente da utilização desse estereótipo pode ser encontrado na reação geral do público brasileiro ao artigo escrito pelo correspondente do New York Times, Larry Rohter, em 2004. Ao reportar que o Brasil está encarando uma onda de obesidade, Rohter não fez nada mais do que relatar informações já divulgadas por fontes brasileiras. Todavia, a reação à matéria do jornalista americano visou castigá-lo como gringo ignorante que nada sabia sobre o Brasil. Nessas denúncias, a 
veracidade das acusações não foi criticada: bastava salientar o status de Rohter como gringo e burro para desqualificar suas opiniões sem que se tivesse que refutá-las de maneira crítica. ${ }^{3}$

Testemunhei vários exemplos do uso do estereótipo do "gringo burro" durante a pesquisa que resultou em minha tese sobre imigrantes anglofalantes no Rio de Janeiro. O mais marcante deles, para mim, foi o de uma informante minha, a "Sara", que tinha sido contratada para trabalhar como dublê de uma famosa apresentadora de programas infantis da TV brasileira. Sara foi taxada de "gringa burra" quando a agência que a empregou tentou destituíla de $80 \%$ de seu salário após o encerramento das filmagens em que trabalhou.

O combinado era Sara receber um salário igual ao que ganhava, na época, como professora de inglês, ou seja, algo em torno de $\mathrm{R} \$ 100$ por dia. Como ela não tinha direito a trabalhar livremente no Brasil (pois na época ainda não havia recebido o seu visto de permanência), não houve contrato além do verbal. No dia do pagamento, porém, Sara descobriu que a agência só tinha pago o equivalente a R\$ 20 diários. Quando reclamou, o empregador alegou que ela não tinha entendido o contrato, pois "você sabe como é: vocês gringos não conhecem bem a nossa língua". Quando Sara revelou que um colega brasileiro estava disposto a testemunhar a seu favor, o argumento da agência mudou de direção, mas não de conteúdo. Continuou apostando na caracterização de Sara como "gringa burra", dessa vez alegando que ela "não entendia como esse tipo de trabalho é feito no Brasil; atrizes principiantes não ganham mais que isto em nosso país". Somente após receber o apoio de vários colegas brasileiros, dispostos a levar o caso a uma instância trabalhista, é que Sara finalmente recebeu o pagamento integral.

O caso da Sara demonstra, novamente, que o preconceito contra $o$ gringo não tem que ser um traço permanente da personalidade para poder ser utilizado como recurso ocasional em momentos de conflito. $\mathrm{O}$ agente contratador, neste caso, estava motivado pela intenção de poupar dinheiro na folha de pagamentos e não por algum desgosto generalizado em relação aos gringos. Nesse jogo, a desqualificação de Sara como "gringa burra" surge simplesmente como uma maneira econômica de desacreditar das suas reivindicações por um salário, de acordo com os padrões estipulados por seu contrato verbal e pelas leis trabalhistas brasileiras.

\section{'Sei como fazem em sua terra"}

O preconceito não é necessariamente reduzido pelo contato com o próprio objeto, fato que também se dá no caso de idéias a priori de brasileiros contra gringos. Aqui enfocamos aqueles brasileiros que têm vivido no exterior ou que têm tido muito contato com estrangeiros e, às vezes, utilizam um tipo específico de preconceito com o objetivo de julgar o gringo pelas normas de seu país de origem. Novamente, se a acusação é verídica ou não, é de importância secundária; importante é que ela redirecione a atenção das reivindicações ou reclamações do estrangeiro, focalizando-a em seu status de gringo.

O exemplo clássico do uso deste tipo de preconceito pode ser visto no argumento do oficial da Polícia Federal que, diante de um gringo que reclama de uma injustiça burocrática, real ou imaginada, responde que "você não deve chorar, pois o que fazem em sua terra com os brasileiros é bem pior". Se a acusação é verídica ou não, ela nada tem a ver com as responsabilidades do oficial perante as leis brasileiras. Novamente, a acusação se configura como exemplo da reclassificação de direitos como privilégios tolerados.

Testemunhei um outro exemplo desse tipo de preconceito quando um grupo de alunos estrangeiros tentou convencer sua universidade da necessidade de providenciar um curso avançado de texto escrito em português. A desculpa oferecida pelo funcionário que impediu o prosseguimento da petição dos alunos foi que ele tinha feito cursos extensivos nos EUA e na Europa e que "não oferecem aulas desse tipo para os alunos estrangeiros nas universidades lá de suas terras". Nessa ocasião, o argumento oficial era completamente errado, já que os cursos de aperfeiçoamento de língua são oferecidos para alunos estrangeiros na maioria das melhores universidades americanas e européias. Novamente, porém, a veracidade da acusação não era importante, sendo que o objetivo do argumento do funcionário era apenas o de bloquear o pedido sem ter que argumentar logicamente contra ele, utilizando o recurso "sei como é que fazem em seus países".

Tal acusação é extremamente comum em argumentos entre brasileiros e estrangeiros, às vezes entrando em discussões que não fazem o menor sentido. Uma vez, por exemplo, vi um barman gringo abordar um freguês brasileiro que não queria pagar integralmente uma conta. $\mathrm{O}$ brasileiro em questão era casado com uma gringa e quando o barman continuou a insistir no pagamento, argumentou que "já vivi em sua terra e sei como as coisas são feitas lá. Mas estamos no Brasil e nem sempre a gente daqui tem o dinheiro que quer. Você vai ter que esperar pela segunda metade de seu pagamento." Registra-se mais uma vez que seja qual for a veracidade da acusação, sua função aqui é a de salientar o status do gringo como alguém que não tem o direito de reivindicar uma conta. Certamente esta é uma maneira bastante original em insistir no fiado!

\section{O Retrato de Dorian Grey}

Uma outra acusação tipicamente empregada contra gringos é a de que eles não são o que parecem ser; que debaixo de uma superfície aparentemente inócua e inocente há um ser profundamente perverso que busca abusar da hospitalidade e da tolerância dos brasileiros para efetivar uma agenda oculta. Esse é o gringo que quer "roubar as riquezas da Amazônia" e que, durante a ditadura, era taxado de "agente da CIA" por universitários esquerdistas. Nos dias de hoje, a acusação dessa natureza mais tipicamente empregada contra os gringos é a de serem pedófilos ou turistas sexuais. Em todos os casos, porém, a manobra é essencialmente 
a mesma: desqualificar o gringo como agente social através de uma acusação desmoralizante que não se sustenta em nada que ele tenha feito, mas sim no que ele poderia estar planejando fazer.

A analista de cultura Freya Johnson fala no "high other", um "outro enaltecido" que existe em contraposição, mas não em contradição, ao já conhecidíssimo "low other", ou "outro rebaixado". De acordo com Johnson, em ambos os estereótipos "[...] existe a construção costumeira do 'outro' [...] para distanciar e proteger o 'eu' de [certas] semelhanças que posso compartilhar com o objeto revoltante[...]" No entanto, diferente da configuração tradicional do "outro rebaixado", a primeira impressão das representações dos "outros enaltecidos" é que eles são atraentes, educados, organizados, bemvestidos, etc. Com mais contato, porém, podemos enxergar que essa impressão é apenas superficial e que o "outro enaltecido" é um maníaco psicopata, com motivações psicológicas alienígenas e repugnantes. Em outras palavras, com os "outros rebaixados", a objetividade é tida como congruente com a subjetividade: gente baixa gosta de baixarias. Por contraste, diante dos "outros enaltecidos", o estereótipo nos informa que eles são subjetivamente diferentes da gente, apesar de certas semelhanças objetivas: eles parecem com "gente normal", mas são de fato perversos. Como no Retrato de Dorian Grey, "outros enaltecidos" podem ser atraentes, mas no fundo de seus corações são maldosos e decadentes. (Johnson: 14).

Acusar o gringo de ser alguém que esconde uma agenda oculta tem muito a ver com o "high other" de Johnson, pois sua aparência inocente esconde uma verdade terrível. E de novo é importante salientar que tal estereótipo é empregado independente de qualquer justificativa baseada no comportamento real do gringo em questão. Sem dúvida alguma, existem gringos pedófilos no Brasil. Devem existir até os que trabalham para a CIA. No entanto, o brasileiro que emprega esse estereótipo certamente pouco se importa se a vítima da acusação é ou não é um espião ou predador sexual; as características de uma minoria insignificante dos gringos são ampliadas para desqualificarem moralmente qualquer gringo com quem o brasileiro se desentenda.

Um de meus informantes, um inglês que recentemente foi premiado por suas obras de caridade entre as crianças das favelas do Rio de Janeiro, foi acusado de pedofilia pelo dono de sua pensão:

"Era para eu pagar 100 dólares por mês. Quando ele pediu 200, recusei e disse que eu mudaria de moradia. Saí em busca de um hotel e, quando voltei à pensão, a polícia estava à minha espera. Acontece que o dono me acusou de ter dormido com uma menor do grupo com o qual eu trabalhava. Eu dizia que isto era um absurdo e que meu trabalho era vistoriado pela Igreja, mas os policiais me diziam 'São sempre os gringos como você, com essa cara de inocente, que são os piores infratores'.- Tive que pagar uma propina enorme, embora a polícia não possuisse prova alguma contra mim, pois me ameaçaram, dizendo que iam me jogar na cadeia, contando para os outros presos que eu era um turista gringo, estuprador de menores. Mais tarde, descobri que a polícia dividiu o dinheiro com o dono da pensão."

Neste caso, uma acusação de pedofilia foi rapidamente mobilizada para ganhar uma disputa em torno do aluguel com um gringo. Uso semelhante a esse estilo "Dorian Grey" foi usado em 1939 para expulsar a etnóloga americana Ruth Landes do Brasil. Landes tinha entrado em atritos com o antropólogo brasileiro Artur Ramos e foi expulsa do país por causa de acusações de violações da ordem moral que aparentemente surgiram, pelo menos parcialmente, em função dessa disputa (Corrêa, 2003:163-177; Landes, 1967). Este tipo de preconceito é provavelmente tão velho quanto a presença estrangeira no Brasil, fato testemunhado, nos arquivos históricos da colônia, de um certo "Thomas babintão ingres. Memorial de todos os Extrangeiros q Vivem nas Cap.as do Rio Grande, Parahyba, Tamaracá \& Pernambuco e Bahia dos quais se não pode ter sospeita. [sic]" (Souza Cruz, 1987:1213). Embora Thomas estivesse acima de qualquer suspeita, essa inscrição de 1618 deixa claro que a maioria dos "extrangeiros" provavelmente não o fossem.

\section{O gringo bom, ou o "nosso" gringo}

Um estereótipo final encontrado por gringos e até utilizado por eles para se defenderem dos outros preconceitos é o que tenho chamado, em outros trabalhos (Blanchette, 2001), de o "gringo bom"-o estrangeiro descrito por seus amigos brasileiros como "quase brasileiro" ou "mais brasileiro que muitos brasileiros" e que geralmente é definido como "alguém que ama, e muito, o Brasil". Esta classificação não deixa de ser preconceituosa, embora no sentido positivo, pois se sustenta em estereótipos e é utilizada como uma espécie de "recompensa" para aqueles estrangeiros que não quebram o consenso social, não entrando em atritos com os nativos.

Em primeiro lugar, os "gringos bons" são aqueles que não contradizem nossas opiniões sobre o mundo. Para quem gosta do Flamengo, o gringo que torce pelo Vasco é um "gringo burro que não sabe nada de futebol", mas para o seu correligionário flamenguista, ele é um "gringo bom, quase um brasileiro". "Gringos bons" são aqueles que mais se assemelham a nós, sem entrarem em conflitos com a nossa visão da vida vivida como brasileiro. Ademais, eles tendem a ser aqueles estrangeiros que estão mais perto de nós em termos de afinidades pessoais. Quanto mais próximo o gringo estiver de um brasileiro, em termos pessoais, profissionais e políticos, maior a chance deste brasileiro referir-se a ele como "quase brasileiro". Essa menção é bastante valorizada por muitos gringos, que se esforçariam com afinco para merecê-la.

Participei de uma demonstração de como as afinidades podem ser chaves na construção da categoria do "gringo bom" em uma ocasião em que saí para uma noitada junto com vários colegas da minha turma no Museu Nacional. Eu estava sentado ao lado de Mateus, um colega sueco da minha idade, tamanho e cor e que dominava um português do mesmo nível que o meu. Do outro lado da mesa, sentavam-se duas colegas brasileiras, uma 
co-orientada do Mateus e a outra minha co-orientada. Começávamos a falar sobre a minha pesquisa e mencionei como era difícil saber quem era ou não gringo em alguns casos.

Magina, Tadeu! - diz a co-orientada de Mateus, enquanto minha colega conversava com o garçom - é óbvio quem é gringo, fora alguns casos particulares. Quero dizer, só de olhar para você, eu consigo ver que você é gringo. Mateus, porém, dá para enganar. Parece até brasileiro. Mas ele é uma raridade.

Neste momento, minha co-orientada voltou à conversa, sem ter ouvido a contribuição de nossa amiga:

"Tadeu-dizia-é bem claro quem é e quem não é gringo na grande maioria dos casos. Você só não acha que é, pois você é um dos poucos gringos que passa por nativo. Mas olha só o Mateus! Como é que alguém poderia ver ele e não achar que fosse gringo?"

\section{Conclusão}

Costumamos entender o preconceito como algo duradouro, fato revelado por uma campanha anti-racista recente que perguntava aos brasileiros: "Onde guarda o seu racismo?" Esta acepção do fenômeno o situa como um desvio psicológico e duradouro, profundamente pessoal, que pode ser atacado através da educação e da conscientização do indivíduo. Todavia, como deve ser óbvio através dos exemplos dados acima, o tipo de preconceito mais encontrado por gringos no Brasil não está necessariamente enraizado num distúrbio moral ou psicológico que vai contra as normas brasileiras de tolerância ou de justiça e muito menos configura-se como característica permanente. Tipicamente, o preconceito é encontrado num emprego estratégico de determinados arquivos de imagens estereotipadas que visam desqualificar um estrangeiro em momentos de conflito, apelando para as caricaturas do gringo, a fim de se esquivar da necessidade de se engajar logicamente aos seus argumentos ou às suas reivindicações.

A característica mais estável desse jogo é o apelo a uma pretensa hierarquia social que "todo mundo" reconhece, na qual o nativo é tido como naturalmente superior ao estrangeiro. Nessa trama, os direitos são (re)-configurados como privilégios, partindo-se do status presumivelmente inferior do estrangeiro diante do nativo, justamente para evitar qualquer discussão que possa desvendar os interesses em conflito. Nesse sistema de valores, é errado dizer-se que o indivíduo é necessariamente preconceituoso quando ele utiliza a linguagem socialmente reconhecida dos preconceitos para defender seus interesses. "Gringo" - igual a outros adjetivos que podem ser usados para mobilizar o preconceito, como "negro" ou "gay" - é geralmente visto no Brasil como uma palavra neutra, na medida em que o indivíduo rotulado é normalizado como "um dos nossos". As qualidades negativas do rótulo somente aparecem em momentos de crise. Portanto, acusar alguém de ser preconceituoso contra os gringos, na maioria dos casos, não tem o menor sentido. Tal acusação seria devolvida junto com uma injunção de que o acusador reconhece que o acusado não pode ser preconceituoso, pois tem à sua disposição vários amigos gringos.

O preconceito contra o gringo, então, revela um fato social recorrente no Brasil: aqui, é possível utilizar-se dos preconceitos de forma estratégica, sem necessariamente incorporá-los como generalização que abrange todos os indivíduos da classe visada, em todos os momentos. Portanto, as intervenções sociais contra o preconceito - calcadas na noção da educação e da sensibilização do indivíduo preconceituoso - hão de arrefecer, na medida em que ignorarem os jogos de interesses por trás da utilização dos preconceitos.

* Thaddeus Blanchette é Doutorando em Antropologia Social - Museu Nacional/UFRJ.

\section{REFERÊNCIAS BIBLIOGRÁFICAS}

ADORNO, Theodor

(1950) The Authoritarian Personality. New York: Harper \& Row.

ALLPORT, Gordon

(1954) The Nature of Prejudice. Reading, Mass. : Addison-Wesley Pub. Co. [1979].

BAUMAN, Zygmunt

(1987) Thinking Sociologically. Belmont,
CA: Wadsworth Pub.

CORREA, Mariza

(2003) Antropólogas \& Antropologia. Belo Horizonte: Editora UFMG.

HOLANDA, Sérgio Buarque de

(1973) Raizes do Brasil. $7^{\text {a }}$ ed. Rio de Janeiro: José Olympio Editora.

DA MATTA, Roberto

(1979) Carnavais, Malandros e Heróis. Rio de Janeiro: Editora Zahar.

DURKHEIM, Émile

(1978) "As regras do método sociológico" In: DURKHEIM. Série Os Pensadores. São Paulo: Abril Cultural.

LANDES, Ruth

(1967) A Cidade das Mulheres. Rio de Janeiro: Editora Civilizaçāo Brasileira.

SOUZA CRUZ COMPANY

(1987) A Presença Britânica no Brasil: 18081914. Rio de Janeiro: Editora Pau-Brasil.

\section{Recursos da internet}

\section{JOHNSON, Freya}

(1995) 'Newt's Nazis: Pop Culture's High Other." In: Bad Subjects: Political Education for Everyday Life. \#33, Setembro, 1995. Versão eletrônica disponivel no http:// eng.hss.cmu.edu/bs.

\section{NOTAS}

1 - Como tenho registrado em outros textos (Blanchette, 2001a; 2001b; 2002), "gringo" é um termo não-pejorativo, geralmente utilizado no Brasil para rotular um estrangeiro em terras brasilis, alguém que "não é nosso, mas está entre nós". Todavia, aqui utilizo o termo num sentido simultaneamente mais amplo e mais restrito do que em meus trabalhos anteriores. Neste artigo, "gringo" refere-se àqueles estrangeiros, residentes no Brasil, -oriundos de nações popularmente entendidas como tendo mais poder e prestígio do que este país no sistema político-econômico internacional. Em particular, falo aqui de gringos nativos dos paises da Europa Ocidental, América do Norte acima do Rio Grande, Austrália, Nova Zelândia $e$, às vezes, África do Sul e Argentina. Nenhum recorte étnico ou de classe está implícito nesse uso do termo "gringo", embora os gringos mais "clássicos" sejam entendidos pela maioria brasileira como brancos e de classe média.

2 - Note-se que o estrangeiro residente ou naturalizado tem o mesmo direito de usufruir do sistema educacional brasileiro que qualquer cidadão nativo.

3- A acusação de que a matéria de Rohter é inválida porque o Times a apresentou com fotografias de turistas tchecas gordas é um desvio da questäo central, já que o jomalista gringo não foi responsável pela inclusão das fotos e os seus argumentos não foram nelas sustentados. A midia brasileira, ao salientar a questão das tchecas, está praticando uma variação mais sofisticada do estereótipo do "gringo burro" para desqualificar as palavras de Rohter. 